\title{
Lordosis reflex, sexual receptivity, and feeding: Estrogen responsivity in male and female rats
}

\author{
ROBERT H. CHAPMAN, JUDITH M. STERN, and JEFFREY A. LIBERT \\ Rutgers-The State University, Busch Campus, New Brunswick, New Jersey 08903
}

Possible sex differences in estrogen responsiveness were tested by administering 10 daily injections of $5 \mu \mathrm{g}$ estradiol benzoate to gonadectomized male and female rats. Although estrogen readily potentiated the manually elicited lordosis reflex in both males and females, neither sex showed high levels of sexual receptivity in the presence of a stud male and sex differences were not significant. Reductions in food intake and body weight during estrogen treatment were at least as great in males as in females. Results were discussed in light of accumulating evidence that the male rat is very responsive to estrogen.

Many lines of evidence indicate that androgen acting during the perinatal period suppresses the behavioral responsiveness of male rats to ovarian steroids in adulthood. For example, the effectiveness of exogenous estradiol benzoate (EB) and progesterone $(\mathrm{P})$ in inducing sexual receptivity is reduced in female rats by neonatal testosterone administration (Barraclough \& Gorski, 1962) and is increased in male rats by neonatal castration (Grady, Phoenix, \& Young, 1965).

Neonatal androgen clearly reduces the sensitivity of neural systems mediating lordosis to P (Clemens, Hiroi, \& Gorski, 1969; Davidson \& Levine, 1969), but sex differences in sensitivity to EB are more controversial. A number of reports indicate that EB more effectively potentiates lordotic responding to a stud male in females than in males or females exposed to androgen neonatally (Edwards \& Thompson, 1970; Gerall \& Kenney, 1970; Hendricks, 1972; Whalen, Luttge, \& Gorzalka, 1971), while others have found no sex difference on this measure (Clemens et al., 1969; Clemens, Shryne, \& Gorski, 1970). In the context of a large-scale experiment on the effects of prenatal stress (Chapman, 1977), it was noted that 5- $\mu \mathrm{g}$ daily EB injections potentiated manual lordosis in male rats as effectively as in females. In light of this finding, the hypothesis of decreased behavioral responsiveness of males to $\mathrm{EB}$, derived largely from stud male tests, bears reexamination.

In the present study, sex differences in the effects of EB were evaluated for the manual lordosis reflex,

This research was supported by National Institute of Mental Health Grant MH-28088, a Biomedical Sciences research grant, and a grant from the Rutgers Research Council, Judith M. Stern, Principal Investigator. The authors wish to thank Dr. Barry Komisaruk for his assistance and the Schering Corporation for supplying the estradiol benzoate and progesterone. Requests for reprints should be addressed to Dr. Judith M. Stern, Department of Psychology, Rutgers College, Rutgers University, New Brunswick, New Jersey 08903. sexual receptivity to a stud male, and for feeding. Although EB has been found to decrease food intake (FI) and body weight (BW) in both sexes, the effects for females have generally exceeded those reported for males (Beatty, Powley, \& KLeesey, 1970; Bell \& Zucker, 1971; Gentry \& Wade, 1976).

\section{METHOD}

\section{Subjects}

The subjects were 10 male and 9 female Sprague-Dawley rats, obtained at $60 \pm 5$ days of age from Blue Spruce Farms, Altamont, New York. After arrival from the breeder, each rat was housed individually in a plastic pan cage measuring $10 \times 7 \times 6$ in. and maintained on a 12:12 light-dark cycle with light onset at 10:15 p.m. Water and Purina Lab Chow, placed on the wire cage lid, were available ad lib. For the duration of the study, each animal's body weight $( \pm 1 \mathrm{~g})$ and food weight $( \pm 0.1 \mathrm{~g})$ were measured daily between 9:00 and 10:30 a.m. Following a 19-20-day adaptation period, each male and female was bilaterally gonadectomized under Equithesin anesthesia. Beginning 3 weeks after gonadectomy, all rats received two daily SC injections of $0.1 \mathrm{ml}$ sesame oil administered about the time of weighing to promote adaptation to the injection procedure. On each of the next 10 days, 7 males and 6 females received $5 \mu \mathrm{g}$ EB dissolved in the oil vehicle. The remaining controls, 3 male and 3 female rats continued to receive oil alone.

On Days 2, 4, 6, 8, 10, and 12 of the injection period (Day 2, oil only; remaining days are $2,4,6,8$, and 10 days, respectively, after onset of EB treatment), each rat received two lordosis tests between 2 and 5 p.m. For the initial (manual lordosis) test, each rat was individually removed from the dark colony room to an adjoining lit room and placed in a 10-gal aquarium containing wood chips. Following a 2-min adaptation period, the experimenter attempted to elicit manual lordosis for three consecutive trials at 1 -min intervals by palpation of the rat's flanks and perineum. The rat's response was rated on the following 4-point scale: 0 -no response; 1 -slight dorsiflexion of the back; 2 -moderate or pronounced dorsiflexion; and 3-pronounced dorsiflexion with head elevation. On the second lordosis trial, a Polaroid photograph of the rat's response was taken through the aquarium glass. Since the rat was positioned directly in front of millimeter-ruled graph paper affixed to the back of the aquarium, the dorsiflexion score of Komisaruk and Diakow (1973) could be calculated [(height of rump - height of back) + (height of nose height of back)].

After all rats had received the manual lordosis test, each was retested under dim red illumination for sexual receptivity, i.e., 


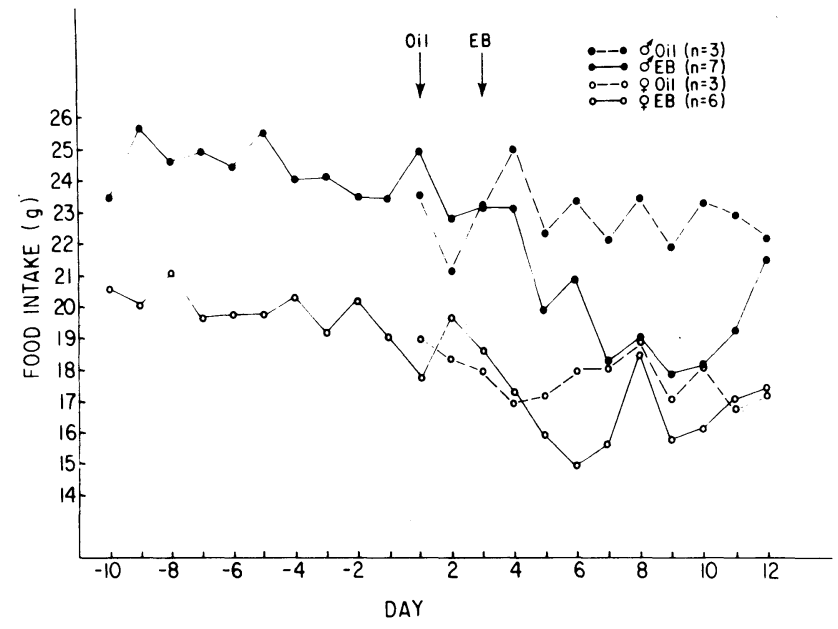

Figure 1. Mean food intake (grams) for gonadectomized male and female rats treated with oil or estradiol benzoate (EB). Days -10 to -1 represent the preinjection period, Days 1 and 2 represent the oil-injection period for all groups, and Days 3-12 represent the experimental injection period in which oil or EB were administered to the appropriate groups.

lordosis to 10 mounts by a vigorous stud male. Following each stud male mount, the response of each subject was rated on the 4-point scale. All data for the experiment were collected without the experimenter's knowledge of each rat's injection treatment.

\section{RESULTS}

\section{Feeding Behavior}

The mean daily food intake suppression in EBtreated males relative to oil-treated males $(\bar{X}=2.85 \mathrm{~g})$ during the estrogen injection period significantly exceeded the mean suppression in EB-treated females relative to oil-treated females $(\bar{X}=0.83 \mathrm{~g}), F(1,9)=$ $17.2, \mathrm{p}<.01$ (Figure 1). EB injections also produced a significantly greater suppression of food intake expressed as percentage of body weight in males than in females relative to their respective oil controls, $\mathrm{F}(1,9)=6.53, \mathrm{p}<.05$.

Sex differences in estrogen responsivity were also evaluated by calculating the percentage of food intake suppression for each EB-treated rat during the 10-day estrogen injection period as compared to the 10-day baseline period immediately preceding injections. The mean percentage reduction in food intake during estrogen treatment did not differ significantly between males $(\overline{\mathrm{X}}=17.9 \%)$ and females $(\overline{\mathrm{X}}=16.4 \%)$, $\mathrm{F}(1,11)=0.4, \mathrm{p}>.10$. Thus, daily administration of $5 \mu \mathrm{g}$ of EB produced a significantly greater suppression of food intake in males than in females as compared to their respective oil-injected controls, but not relative to their preinjection baseline.

\section{Body Weight}

EB treatment reversed the weight gain evident during the preinjection period for both males and females (Table 1). Ten days of EB treatment produced a similar net weight loss in males $(\overline{\mathrm{X}}=7.5 \mathrm{~g})$ and females $(\bar{X}=7.7 \mathrm{~g})$ relative to their respective means for the preceding 2 days of oil injection. Since the control males gained weight faster than the control females, the mean daily weight loss of EB-treated males relative to their oil controls $(\bar{X}=1.36 \mathrm{~g})$ exceeded the mean difference between EB and oil females $(\overline{\mathrm{X}}=1.05 \mathrm{~g})$, but this sex difference did not quite reach statistical significance, $F(1,9)=3.52$, $\mathrm{p}<.10$.

\section{Sexual Behavior}

Neither manual stimulation nor mounting by a stud male elicited lordoses in any oil males (Figure 2A). Oilinjected females, however, did exhibit low-level lordoses to $22 \%$ of the manual stimulation trials, but seldom responded to stud male mounts.

Estrogen treatment effectively potentiated manual lordoses in both males (Figure 2B) and females (Table 2). On the first EB test, approximately $28 \mathrm{~h}$ after the first and $4 \mathrm{~h}$ after the second EB injection, the majority of males and females showed low-quality lordoses to manual stimulation. Following 6 days of EB treatment, manual stimulation elicited high-quality lordoses (rated 2 or 3 ) in $100 \%$ of the test trials. Despite continued daily EB administration, the responsiveness of males and females waned on Test Days 8 and 10 .

The sum of lordosis ratings on the manual test over the three trials and the dorsiflexion score calculated from photographs were each analyzed for EB-treated rats via a 2 (sex) by 5 (test days) ANOVA. Although EB females averaged higher scores than EB males on both measures, sex differences were not significant $[F(1,11)=1.20$ and 0.02 for lordosis rating and dorsiflexion score, respectively, $\mathrm{p}>.10$ ], nor did the Sex by Test Day reach significance ( $F<1$ for both measures).

The daily EB injections did not produce high levels of sexual receptivity in stud male tests (Table 2). Most of the males and females actively resisted

Table 1

Mean Body Weight in Grams for Each Group and Treatment Period

\begin{tabular}{lccccc}
\hline Group & N & Pretreatment* & Oil $* *$ & Day 5 $\dagger$ & Day 10 $\dagger$ \\
\hline Males & & & & & \\
EB & 7 & 377.9 & 392.5 & 389.4 & 385.0 \\
Oil & 3 & 371.5 & 388.9 & 399.3 & 407.3 \\
Females & & & & & \\
EB & 6 & 252.6 & 265.9 & 259.0 & 258.2 \\
Oil & 3 & 241.7 & 255.5 & 259.3 & 263.7 \\
\hline
\end{tabular}

*Mean for the 10 baseline days preceding oil injection. **Mean for the 2 days of oil injections preceding the experimental period. TMeans for Day 5 or Day 10 of the experimental period (Days 7 and 12 on Figure 1). Groups received oil or EB as indicated. 

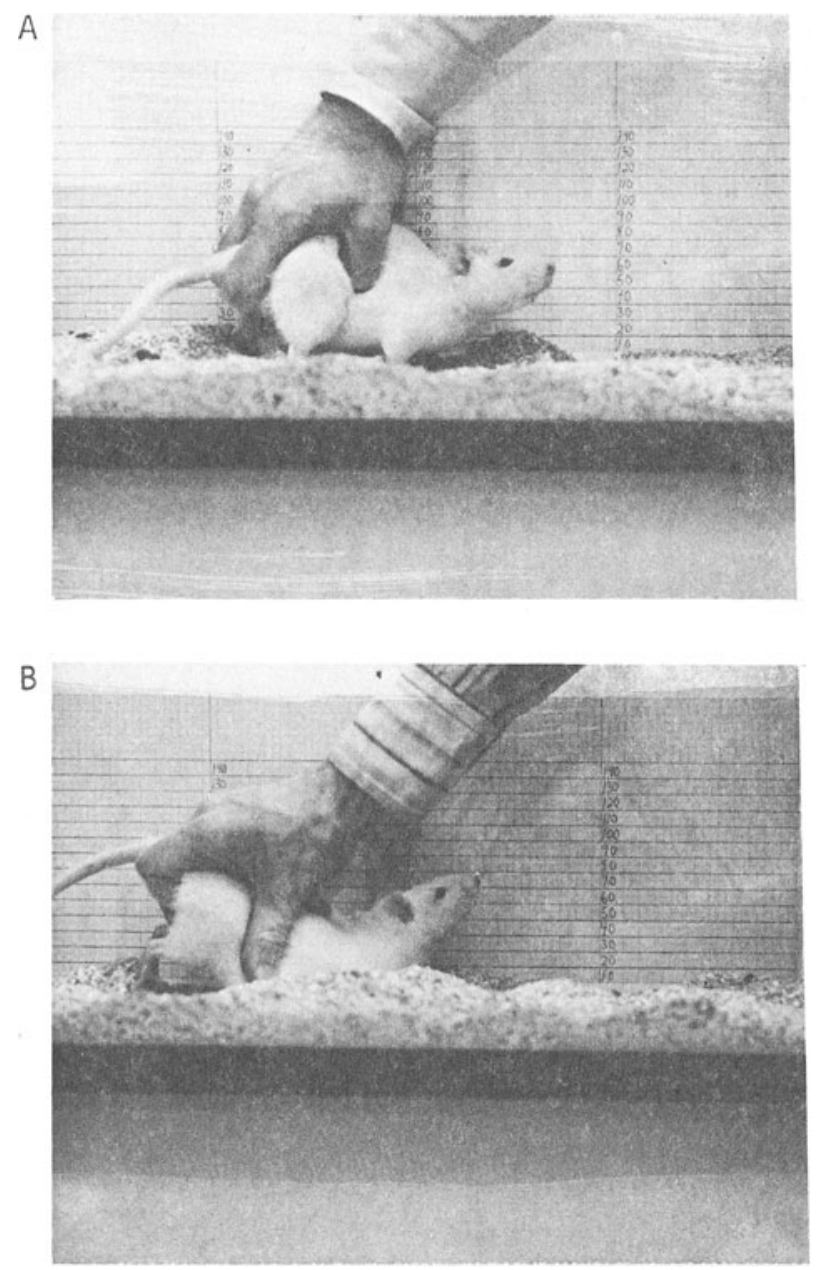

Figure 2. Photographs of attempts to elicit manual lordosis in a castrated male rat following 2 days of oil injection (A) and 6 days of $5 \mu \mathrm{g} \mathrm{EB}$ treatment (B). Note the pronounced lordosis response following estrogen treatment and the millimeter-ruled graph paper used to calculate the dorsiflexion score as described in the text.

mounts by the stud, and none showed any soliciting behavior (darting or ear-wiggling). The mean lordosis quotients $(\mathrm{LQ}=$ lordoses $/$ mounts $\times 100)$ for males and females were only 12.8 and 20.3 , respectively, far below the LQs found for manual stimulation.
The Mann-Whitney $U$ test, performed on summed LQs or rating scores for each EB male and female, was used to test sex differences, because the large number of 0 scores precluded analysis of variance. Sex differences were not significant for either LQ, $\mathrm{U}(6,7)=13.5, \mathrm{p}=.16$, or lordosis rating, $\mathrm{U}(6,7)=$ $13.0, \mathrm{p}=.15$.

\section{DISCUSSION}

Adult gonadectomized male and female rats both responded to daily injections of $5 \mu \mathrm{g}$ EB with a significant facilitation of lordosis and a depression of food intake and body weight, but the direction of sex differences in responsivity depended on the behavior measured. For both manual (reflex) and stud male (receptivity) tests, EB-treated females showed slightly (but nonsignificantly) greater lordosis frequency and quality than EB-treated males. However, the effects of estrogen on food intake and body weight, measured during the same injection period, were at least as great for males as for females, despite the fact that the heavier males received a smaller weight-percentage dose of estrogen.

Injecting smaller daily doses of EB, ranging from 0.5 to $2.0 \mu \mathrm{g} /$ day, other investigators (Beatty et al., 1970; Bell \& Zucker, 1971; Gentry \& Wade, 1976) have reported greater reductions in food intake or body weight for females than for males or neonatally androgenized females. The disparate findings of the present study suggests that while females may show greater sensitivity to the food-intake suppressing effects of small doses of estrogen, males exhibit an equal or greater responsivity to higher levels. Findings pertaining to the possible effect of neonatal testosterone in depressing the responsivity of the body weight-regulating mechanism to endogenous estrogen and progesterone are also inconsistent. Although Bell and Zucker (1971) reported that neonatally androgenized females gained less weight than control females following adult ovariectomy, Beatty et al. (1970) found no differential weight gain. Further experimentation with a variety of weightproportional doses of EB will be necessary to

Table 2

Effects of $5 \mu \mathrm{g}$ EB Injections on Manual and Stud Male Elicited Lordoses for Males and Females on 5 Treatment Days

\begin{tabular}{|c|c|c|c|c|c|c|c|c|c|c|}
\hline \multirow[b]{3}{*}{ Test } & \multicolumn{5}{|c|}{ Males $(\mathrm{N}=7)$} & \multicolumn{5}{|c|}{ Females $(\mathrm{N}=6)$} \\
\hline & \multicolumn{5}{|c|}{ EB Injection Day* } & \multicolumn{5}{|c|}{ EB Injection Day* } \\
\hline & 2 & 4 & 6 & 8 & 10 & 2 & 4 & 6 & 8 & 10 \\
\hline $\begin{array}{l}\text { Manual Test } \\
\text { LQ } \\
\text { Lordosis Rating } \\
\text { Dorsiflexion Score }\end{array}$ & $\begin{array}{l}52 \\
.62 \\
1.0\end{array}$ & $\begin{array}{l}86 \\
1.52 \\
36.3\end{array}$ & $\begin{array}{l}100 \\
2.10 \\
47.3\end{array}$ & $\begin{array}{l}100 \\
1.86 \\
35.0\end{array}$ & $\begin{array}{c}100 \\
1.81 \\
43.6\end{array}$ & $\begin{array}{l}61 \\
9.83\end{array}$ & $\begin{array}{c}100 \\
1.78 \\
33.3\end{array}$ & $\begin{array}{l}100 \\
2.50 \\
46.7\end{array}$ & $\begin{array}{l}94 \\
1.94 \\
41.3\end{array}$ & $\begin{array}{l}100 \\
2.11 \\
36.7\end{array}$ \\
\hline $\begin{array}{l}\text { Stud Male Test } \\
\text { LQ } \\
\text { Lordosis Rating } \\
\text { Number Responding }\end{array}$ & $1^{6} .07$ & $1^{13} .16$ & $3^{.37}$ & $3^{11} .13$ & $3^{9} .09$ & $0^{.00}$ & $2^{8} .12$ & $3^{.28}$ & $4^{33} .52$ & $5^{.65}$ \\
\hline
\end{tabular}

${ }^{*} E B$ Injection Days 2, 4, 6, 8, and 10 correspond to Days 4, 6, 8, 10, and 12 of Figure 1. 
resolve the question of sex differences in estrogen sensitivity for food intake and body weight.

In the present study we found a marked difference between the effectiveness of manual and stud male lordosis tests. While manual stimulation elicited a high-quality lordosis on virtually every test trial by the sixth EB injection day, the highest stud male LQ recorded for males or females on any test day was 40. In the presence of a vigorous stud, none of these rats manifested any soliciting behavior and most actively resisted attempts to mount. These results suggest a clear dissociation between sexual receptivity, defined by Beach $(1977$, p. 125) as "those feminine reactions which are necessary and sufficient for fertile copulation with a potent male," and the lordosis reflex per se. Similarly, Adler and Bell (1969) have reported that constant estrus rats manifest a vigorous manual lordosis reflex but not necessarily sexual receptivity.

The results of the present study suggest that sexual receptivity is dependent on higher titers of estrogen than the lordosis reflex. In females, Komisaruk and Diakow (1973) have further demonstrated that the lordosis reflex elicited by palpation with cervical probing is at least as sensitive to estrogen as vaginal cornification. However, vaginal cornification can be produced by EB doses too small to promote full sexual receptivity in stud male tests (Davidson, Smith, Rodgers, \& Bloch, 1968).

The manifestation of sex differences in estrogeninduced sexual receptivity apparently requires a higher dosage of EB than employed here. In agreement with the present results, Clemens et al. $(1969,1970)$ found that low daily doses of EB ( $2 \mu \mathrm{g}$ given for 3 days) did not produce high levels of receptivity in male or female rats. Higher doses of estrogen, however, reliably produce high levels of sexual receptivity in females but not in males or neonatally androgenized females (Edwards \& Thompson, 1970; Hendricks, 1972; Whalen et al., 1971). However, as indicated by Kow and Pfaff (1975), high levels of estrogen mimic the action of progesterone in facilitating sexual receptivity after a priming exposure to a low dose of estrogen.

The present report adds to the accumulating evidence that the male rat is very sensitive to estrogen. Small doses of EB have previously proven effective in promoting manual lordoses (Sodersten \& Larsson, $1974)$ and also in stimulating wheel-running (Gentry $\&$ Wade, 1976). When combined with the peripherally potent androgen dihydrotestosterone, small quantities of EB will restore the complete pattern of male copulation in castrated male rats (e.g., Baum \& Vreeburg, 1973). Estrogen inhibits luteinizing hormone more effectively than testosterone in male rats (Paup, Mennin, \& Gorski, 1975). Thus, while the hypothesis that perinatal androgen reduces neural sensitivity to estrogen in the male rat has received some empirical support for sexual receptivity, it may not apply to many other behaviors or neuroendocrine functions.

\section{REFERENCES}

Adler, N. T., \& Bell, D. Constant estrus in rats: Vaginal, reflexive, and behavioral changes. Physiology and Behavior, 1969, 4, 151-153.

Barraclough, C. A., \& Gorski, R. Studies on mating behavior in the androgen-sterilized female rat in relation to the hypothalamic regulation of sexual behavior. Journal of Endocrinology, 1962, 25, 175-182.

Baum, M. J., \& VReEberg, J. T. M. Copulation in castrated male rats following combined treatment with estradiol and dihydrotestosterone. Science, 1973, 182, 283-285.

BEACH, F. A. Sexual attractivity, proceptivity, and receptivity in female mammals. Hormones and Behavior, 1976, 7. 105-138.

Beatty, W. W., Powley, T. L., \& Keesey, R. E. Effects of neonatal testosterone injection and hormone replacement in adulthood on body weight and body fat in female rats. Physiology and Behavior, 1970, 5, 1093-1098.

Bell, D. D., \& Zucker, I. Sex differences in body weight and eating: Organization and activation by gonadal hormones in the rat. Physiology and Behavior, 1971, 7, 27-34.

Chapman, R. H. Maternal stress and pituitary-adrenal activation in rats. Possible role in demasculinizing morphology and behavior of male offtspring. Unpublished doctoral dissertation, Rutgers University, 1977.

Clemens, L. G., Hiroi, M., \& Gorski, R. A. Induction and facilitation of female mating behavior in rats treated with low doses of testosterone propionate. Endocrinology, 1969, 84, 1430-1438.

Clemens, L. G., Shryne, J., \& Gorski, R. A. Androgen and development of progesterone responsiveness in male and female rats. Physiology and Behavior, 1970, 5, 673-678.

Davidson, J. M., \& Levine, S. Progesterone and heterotypical sexual behaviour in male rats. Journal of Endocrinology, 1969, 44, 129-130.

Davidson, J. M., Smith, E. R., Rodgers, C. H., \& Bloch, G. J. Relative thresholds of behavioral and somatic responses to estrogen. Physiology and Behavior, 1968, 3, 227-229.

Edwards, D. A., \& Thompson, M. L. Neonatal androgenization and estrogenization and the hormonal induction of sexual receptivity in rats. Physiology and Behavior, 1970, 5, 1115-1119.

Gentry, R. T., \& WADE, G. N. Sex differences in sensitivity of food intake, body weight, and running-wheel activity to ovarian steroids in rats. Journal of Comparative and Physiological Psychology, 1976, 90, 747-754.

Gerall, A. A., \& Kenney, A. McM. Neonatally androgenized females' responsiveness to estrogen and progesterone. Endocrinology, 1970, 87, 560-566.

Grady, K. L., Phoenix, C. H., \& Young, W. C. Role of the developing rat testis in differentiation of the neural tissues mediating mating behavior. Journal of Comparative and Physiological Psychology, 1965, 59, 176-182.

HENDRICKS, S. E. Androgen modification of behavioral responsiveness to estrogen in the male rat. Hormones and Behavior, 1972, 3. 47-54.

KomisaruK, B. R., \& Diakow, C. Lordosis reflex intensity in rats in relation to the estrous cycle, ovariectomy, estrogen administration and mating behavior. Endocrinology, 1973, 93, 548-557.

Kow, L. M., \& Pfaff, D. W. Induction of lordosis in female rats: Two modes of estrogen action and the effect of adrenalectomy. Hormones and Behavior, 1975, 6, 259-276. 
Paup, D. C., Mennin, S. P., \& Gorski, R. A. Androgen and estrogen induced copulatory behavior and inhibition of luteinizing hormone $(\mathrm{LH})$ secretion in the male rat. Hormones and Behavior, 1975, 6, 35-46.

Sodersten, P., \& LARsson, K. Lordosis behavior in castrated male rats treated with estradiol benzoate or testosterone propionate in combination with an estrogen antagonist, MER-25, and in intact rats. Hormones and Behavior, $1974,5,13-18$.
Whalen, R. E., Luttge, W. G., \& Gorzalka, B. B. Neonatal androgenization and the development of estrogen responsivity in male and female rats. Hormones and Behavior, 1971, 2 , 83-90.

(Received for publication April 12, 1977; accepted July 5, 1977.) 